\title{
Gliomatosis peritonei caused by ovarian teratoma
}

\author{
R. W. FORTT AND I. K. MATHIE \\ From the Departments of Morbid Anatomy and Obstetrics and Gynaecology, Royal Postgraduate Medical \\ School of London
}

SYNOPSIS A case of ovarian teratoma which produced glial peritoneal deposits is described. Twelve $\overrightarrow{\vec{\omega}}$ other cases in the literature are tabulated. The age at presentation ranges from 22 months to 22 응 years (mean age 14.6 years). The primary tumour may be solid or cystic. The prognosis does not? appear to be improved by radical surgery as opposed to simple excision but depends mainly on the N maturity of the tissues of the primary tumour and the peritoneal deposits. Although the period of $f_{\omega}^{\omega}$ follow up is generally short, a survival time up to 26 years is recorded. In the fatal cases, there is $\underset{\infty}{+}$ rapid recurrence and metastatic spread. The pathogenesis of the glial deposits is discussed.

Ovarian teratomas constitute between 5 and $25 \%$ of ovarian tumours (Blackwell, Dockerty, Masson, and Mussey, 1946; Peterson, 1957; Hertig and Gore, 1961 ), and are bilateral in 10 to $15 \%$ of cases. The majority are cystic and behave in a benign fashion. Malignant change occurs in a small proportion of cystic tumours, usually less than $2 \%$ (Peterson, 1957; Kelley and Scully, 1961; Evans, 1966), with a peak incidence in the fifth and sixth decades. Malignant change usually affects the epidermal component (88\%, Peterson) but more rarely carcinoid tumour (Stewart, Willis, and De Saram, 1939; Kelley and Scully, 1961), malignant melanoma (Marcial-Rojas and Ramirez de Areuano, 1956), sarcoma (Kelley and Scully, 1961), and thyroid carcinoma (Woodruff and Markley, 1957) have been reported. Solid or polycystic teratomas of the ovary are much rarer, $0.2 \%$ of all ovarian tumours (Thurlbeck and Scully, 1960). They occur in younger age groups (children, adolescents, and young adults) and comprise $15 \%$ of all ovarian tumours of childhood (Thurlbeck and Scully, 1960). They usually show microscopic evidence of malignancy and spread rapidly to other sites with almost uniformly fatal results. Recently Peterson (1956) and Thurlbeck and Scully (1960) emphasized that the presence of only well differentiated tissues in solid and polycystic teratomas may indicate a relatively good prognosis. Benirschke, Easterday, and Abramson (1960), on the other hand, had three patients with solid ovarian teratomas with well differentiated tissues in both primary tumour and metastases; two of the patients died within a year of presentation. Luse and Vietti $<$ (1968) reported a similar case in which death oc- $\vec{\oplus}$ curred 19 months after operation. The third and 8 rarest manifestation of malignancy in ovarian tera- $\square$ tomas is represented by peritoneal tumour deposits often predominantly of one type; implants of thyroid tissue or neuroglia have been recorded. A case of gliomatosis peritonei produced in this way is re- $\mathbb{D}$ ported and the literature reviewed.

\section{CASE HISTORY}

Mrs M.L., aged 18 years, started to complain of symptoms on her honeymoon. She noticed an abdominal swelling for some weeks and this had become painful over the few days before admission. She had no other symptoms Her menses were normal and she had had no previous? operations or gynaecological investigations. A tender, $\frac{0}{3}$ nodular mass arising from the pelvis about the size of $a_{0}$ 24-week pregnancy was palpated. At laparotomy there was an excess of peritoneal fluid. The left ovary, which was completely replaced by a cystic tumour, was removed. The right ovary was enlarged and contained a small cyst. $\bar{N}$ Cystectomy was performed and the ovary reconstructed. $v$ Small foci considered to represent tumour deposits 0 were found on the right utero-sacral ligament, the N posterior surface of the uterus, and in the pouch of Douglas. They formed sessile grey-white nodules ( 2 to 8 $\mathrm{mm}$ diameter) on the peritoneal surface without gross invasion of deeper tissues. These nodules were excised. $\bar{\complement}$ In the postoperative period the patient was given? parenteral methotrexate, $\mathbf{4 0} \mathrm{mg}$ daily, for four days.

Seven weeks after operation she was found to have a $\bar{O}$ mass to the right of the uterus, and at a second laparotomy it was found to consist of adherent loops of $\frac{\mathbb{D}}{\mathbb{Q}}$ bowel. The right ovary was enlarged to the size of a plum by a corpus luteum and oophorectomy was performed. 


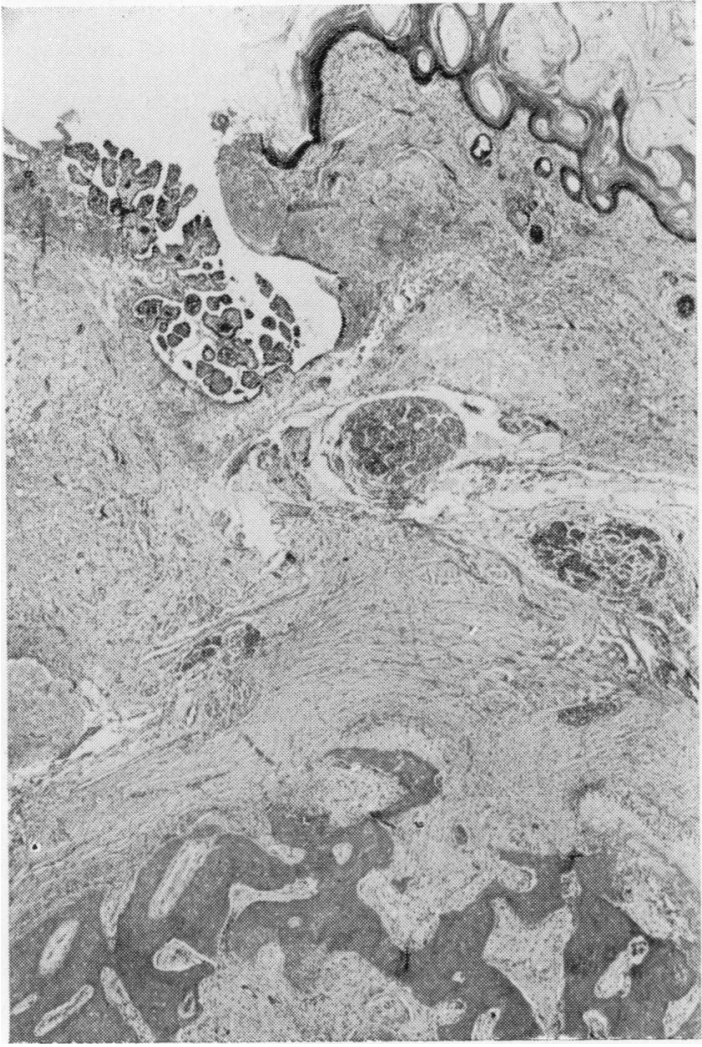

FIG. 1.

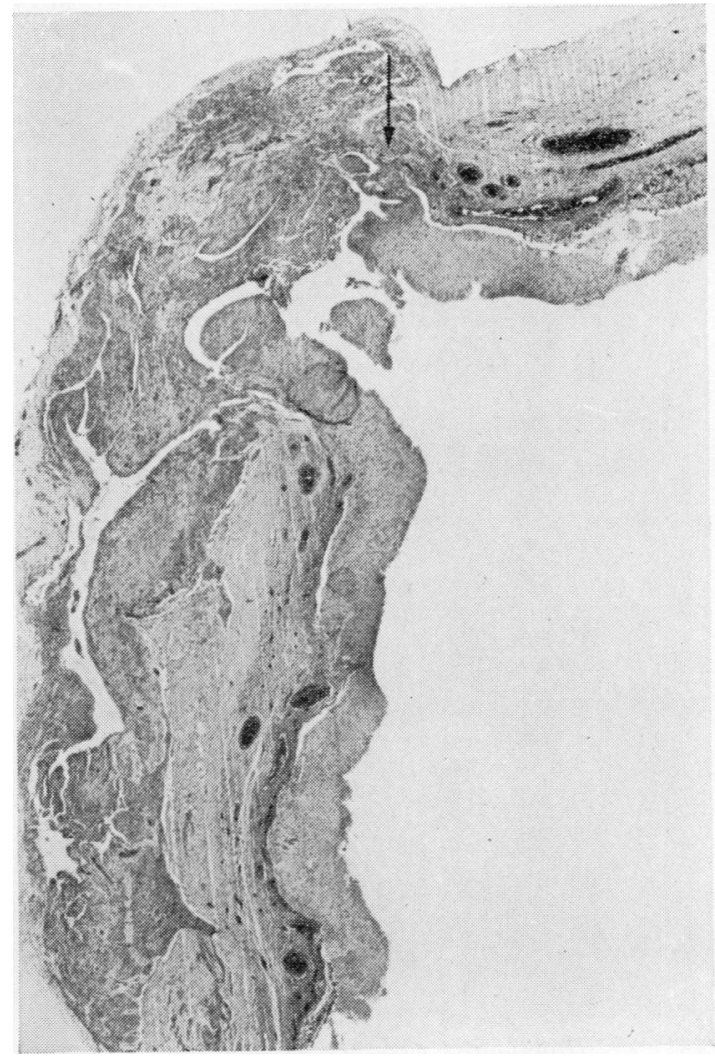

FIG. 2 .

FIG. 1. Portion of the solid structure in the cyst wall showing a mixture of tissues. The cyst lining of skin, choroid plexus, and glia are in direct continuity. There is poorly formed bone in the deeper tissue. (Haematoxylin and eosin $\times 24$.)

FIG. 2. The inner glial lining is seen extending directly through the cyst wall. (Haematoxylin and eosin $\times 40$.)

There was no sign of further peritoneal deposits. The patient has been followed up for 18 months and is alive and symptom-free. Cyclical bleeding is being induced by oestrogens.

\section{MACROSCOPIC FEATURES}

LEFT OVARY This consisted of an opened, unilocular cystic mass $(15 \mathrm{~cm}$ diameter) with a portion of partly skin-covered solid tissue $(8 \times 7 \times 3 \mathrm{~cm})$ in its wall. In addition there were two smooth, glistening, light brown solid polypoid structures projecting into the cyst lumen. A single greyish plaque $(1.3 \mathrm{~cm}$ diameter $)$ was present on the outer surface of the cyst wall.

RIGHT OVARY This was part of the right ovary $(2.7 \times$ $2.2 \times 1.5 \mathrm{~cm})$ with a cyst $(0.9 \mathrm{~cm}$ diameter $)$ and a plaque of tissue on its surface, $0.3 \mathrm{~cm}$ in diameter.

PERITONEAL DEPOSITS Small nodules varied from a few millimetres to $8 \mathrm{~mm}$ diameter. 

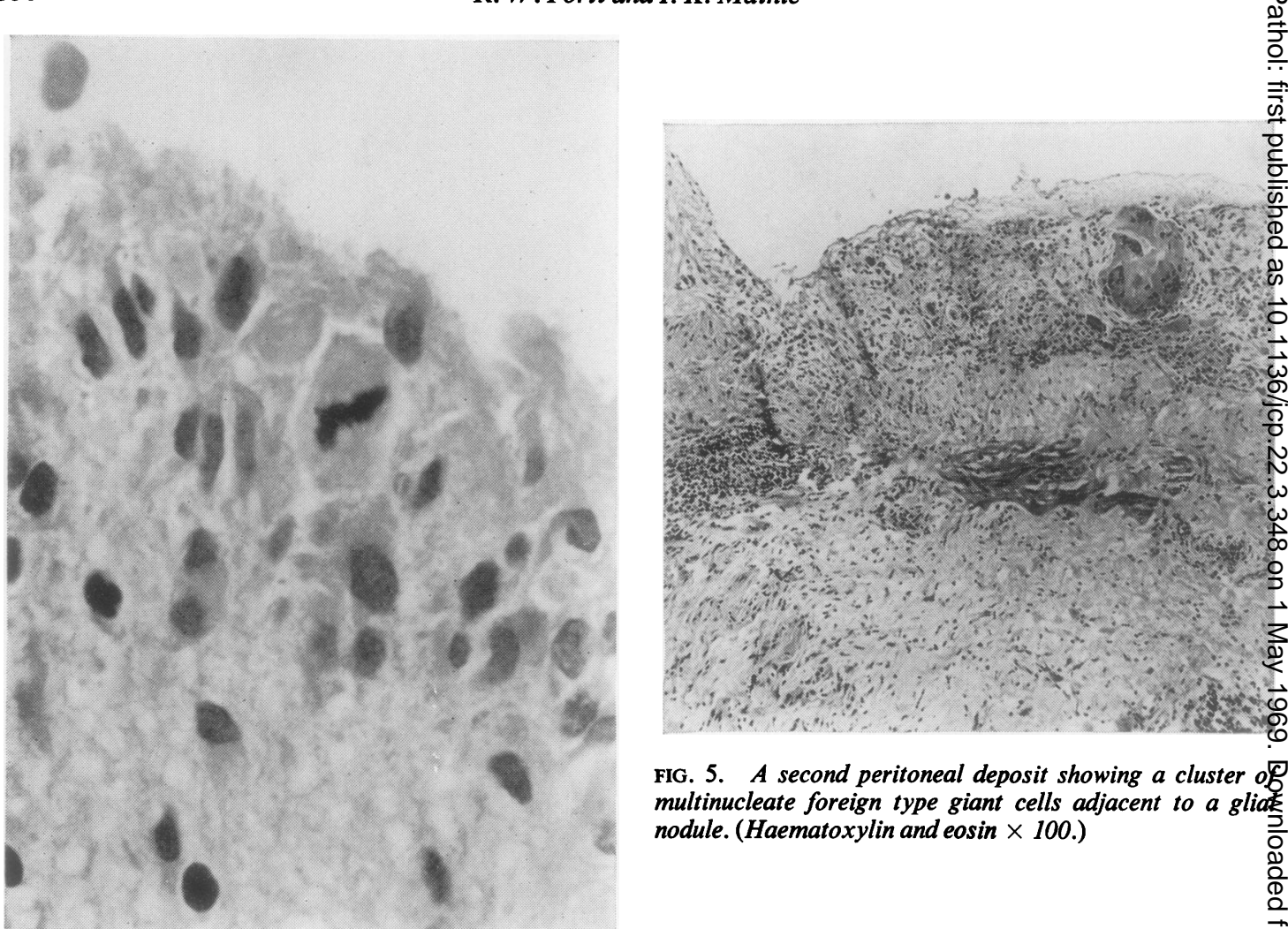

FIG. 3. High-power view of area in Fig. 2 (arrowed)

FIG. 5. A second peritoneal deposit showing a cluster of multinucleate foreign type giant cells adjacent to a glia nodule. (Haematoxylin and eosin $\times 100$.)

showing a mitosis in the glia. (Haematoxylin and eosin $\times 1,000$.)

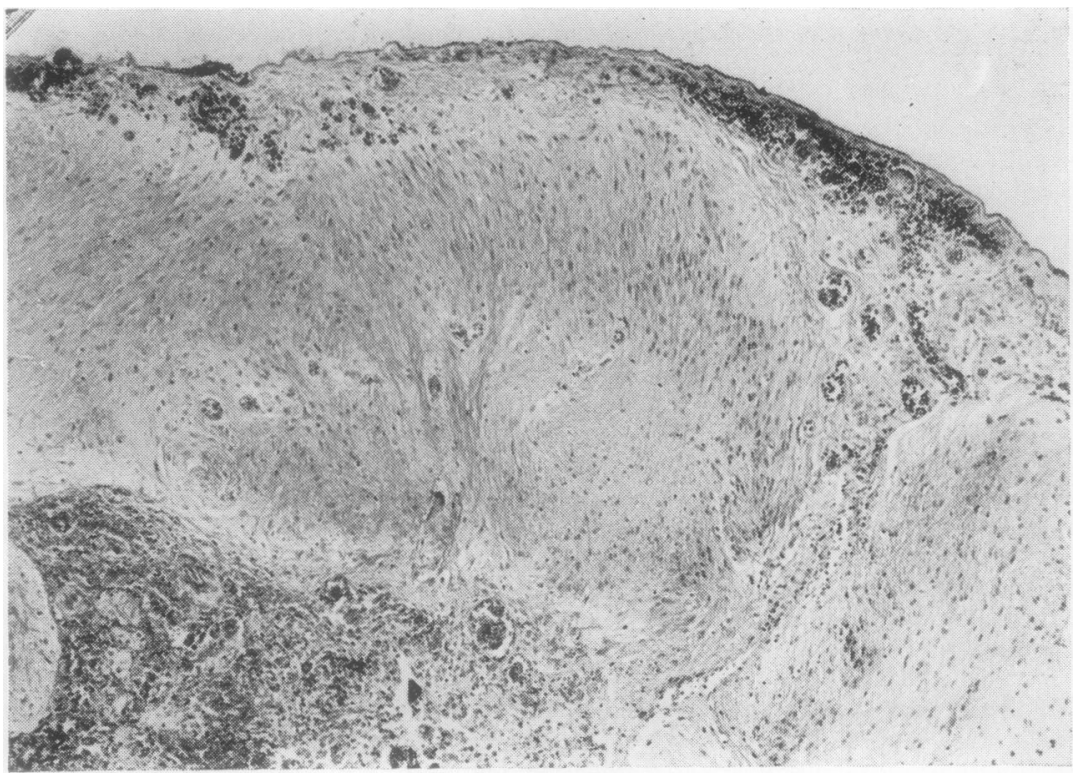

FIG. 4. A glial peritoneal $\frac{7}{2}$ deposit with an underlying lymphoid infiltrate. (Phosphotungstic acidhaematoxylin $\times 100$.) 
deposit of mature glial tissue. This may have been attached to the site of follicular rupture, since siderophages were present at this site.

PERITONEAL DEPOSITS These showed a strip of mesothelium with underlying glial nodules. A little lymphoid tissue was present in the deeper parts (Fig. 4). Two small, gland-like structures, probable ependymal, were present in one nodule. In another a small focus of foreign-body type giant cells was present adjacent to the glial tissue (Fig. 5).

\section{DISCUSSION}

An ovarian teratoma with glial peritoneal deposits is a rare occurrence, and a review of the literature since 1905 revealed only 12 other documented cases. Although neuroglia is a common component of benign teratomas, malignant change in it is dis- tinctly rare. Peterson (1957), in a review of malignant change in 222 benign cystic ovarian teratomas, found only one in which malignancy affected the glial component. In most cases with glial peritoneal deposits the primary tumours contain multiple mature tissues while the peritoneal deposits are mostly small (miliary) and composed entirely of mature glia with occasional gland-like structures resembling ependyma.

The accepted cases of gliomatosis peritonei are listed in Table I.

Age at presentation ranged from 22 months to 22 years. The youngest patient was 22 months old when the peritoneal glial nodules were found. When laparotomy and biopsy of an ovarian tumour had been carried out seven months previously, no peritoneal deposits were noted. At a second laparotomy there was a scar in the wall of the

TABLE I

DOCUMENTED CASES OF GLIOMATOSIS PERITONEI CAUSED BY OVARIAN TERATOMAS

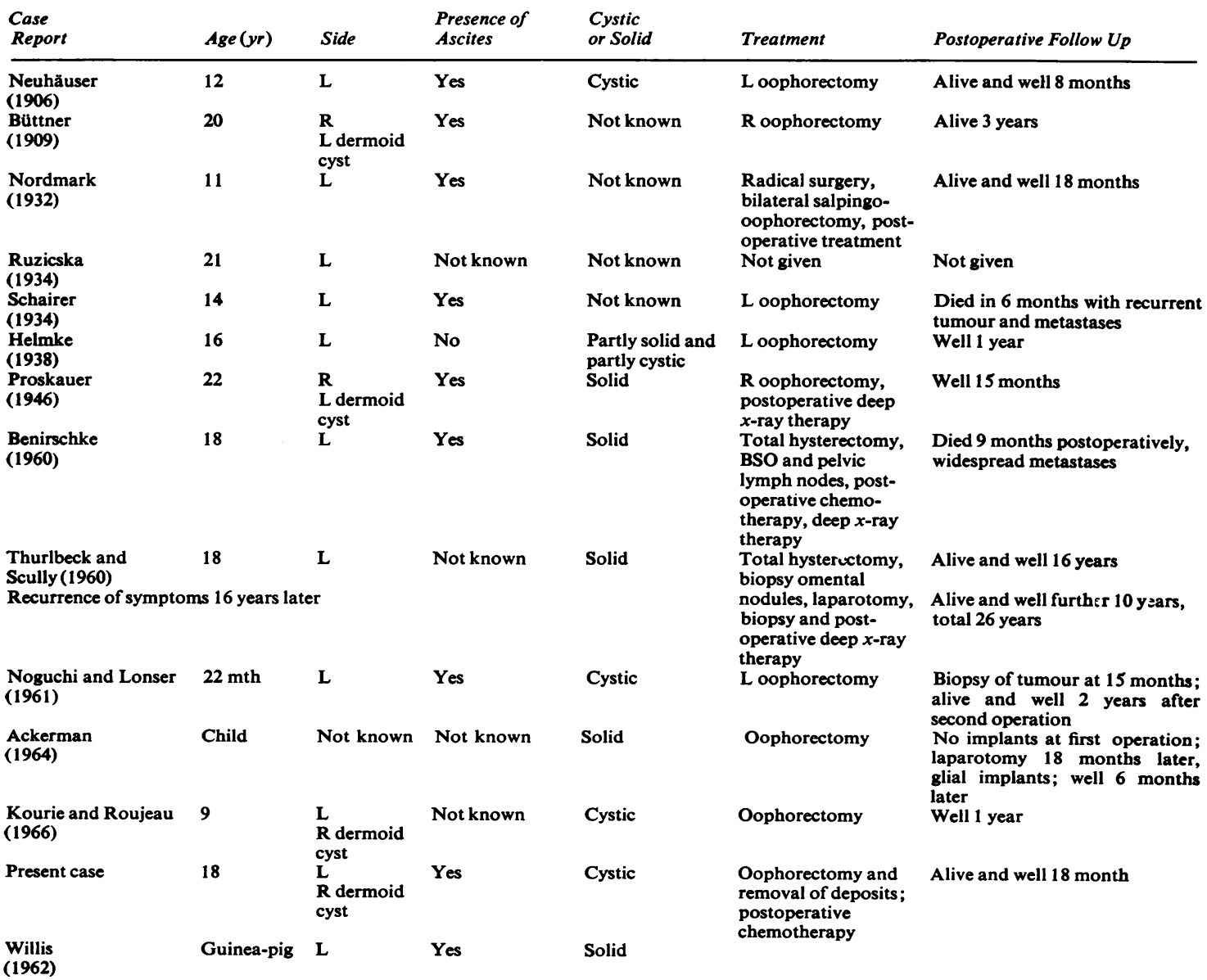


ovarian tumour and the omentum contained numerous small, grey-white glial nodules ( 2 to $3 \mathrm{~mm}$ diameter). Small nodules of glial tissue were also seen in omental lymphatics. Ackerman's case (1964) had an oophorectomy, and, 18 months later at a second laparotomy, glial omental implants were present. The case of Kourie and Roujeau (1966) was also unusual. The omental nodules were composed of glial tissue and a few nerve cells, but small foci of tumour were also seen in the peripheral sinuses of lymph nodes. Neuhäuser (1906) found tumour nodules in a vascular distribution and tumour apparently within lymphatics. All the cases surviving at the time of reporting contained well differentiated tissues in the primary tumour and mature glial tissue in the peritoneal implants. Treatment did not appear to affect the prognosis, and radical surgery appeared to have no advantage over simple removal of the tumour. It was known that peritoneal deposits were left behind at operation in some patients. The longest survival was seen in case 3 of Thurlbeck and Scully. At the first operation peritoneal metastases were only biopsied, and the patient remained well for 16 years, when pelvic, peritoneal, and retroperitoneal masses were noted. At a second laparotomy only one of a number of teratomatous cysts were removed. Postoperative radiotherapy was given, the patient remaining well for a further 10 years without clinical increase in size of the tumour masses. The authors questioned the value of radiotherapy. In Benirschke's case 2, despite good tissue differentiation in the primary tumour and other deposits, there was already spread to iliac lymph nodes, the mesosalpinx, and uterine serosa at the first operation. Despite radiation and chemotherapy the patient died nine months after operation. At necropsy there were tumour deposits over the peritoneum, pleura, and pericardium, and metastases in the paraaortic lymph nodes and the lungs. Microscopically these consisted predominantly of glia, although small foci of other elements were found; all appeared well differentiated. Luse and Vietti (1968) reported a similar case which had well differentiated tissues in the primary tumour and in numerous recurrences. Electron microscopy showed no difference from normal tissues and the only changes in the neural tissue were degenerative, similar to senile changes in the aging brain. In the recurrent tumour all germ layers were represented, neural tissue being prominent but mingled with other elements. Because of uncertainty as to the amount of neural tissue in this case it has been excluded from the table. A very similar case (Fleischmann, 1905) is also excluded from Table I because the primary tumour site was not ovarian. The fate of Ruzicska's (1934) case 2 is unknown. The second definitely fatal case was recorded by Schairerô (1937). In the metastases were many different tissue types, dominantly immature, including immature glial tissue. The cutaneous metastases showed ex-O tensive haemorrhagic necrosis and contained mucussecreting epithelium, fibrous tissue, and cartilage, $\frac{\bar{\rho}}{\bar{\alpha}}$ but the larger part consisted of immature neural $\Phi_{\Omega}^{\infty}$ tissue including rosettes. Barry (quoted by Proskauer, 1946) described a fatal case in which the glia had a 'marked malignant appearance, similar to a glio-. blastoma'.

It appears that the prognosis of patients with $\stackrel{\omega}{\rho}$ gliomatosis peritonei is fairly good when mature tissues only are found in the primary tumouri and the peritoneal deposits. That there are excep- $N$ tions to this generalization is shown by Benirschke's $\omega$ case. Since the follow-up period was short in most $\stackrel{+}{\infty}$ cases confirmation of this conclusion depends on 을 longer study of further cases. The presence of im- mature tissues as recorded by Schairer (1937) and $z$ Barry, quoted by Proskauer (1946), indicates a bad prognosis. The course in these fatal cases is $\vec{\varphi}$ similar to that seen with malignant solid teratomas.

The significance of the few mitoses in the present case is uncertain, and a guarded prognosis was $O$ given. Tentatively we would place it in the group of gliomatosis peritonei with a better prognosis.

The mechanism of how the peritoneal deposits are $\frac{0}{\varnothing}$ formed is uncertain. Willis (1951) states that malig- $\stackrel{\square}{\square}$ nancy and metastatic proclivities in teratomas are of $\overrightarrow{\overrightarrow{0}}$ three kinds: (1) total malignancy, (2) malignancy of 3 one component of a previously benign teratoma, and (3) peritoneal dissemination of relatively benign teratomatous tissues. Schairer's and Benirschke's cases with a fatal outcome could represent mere variants of solid malignant teratomas in which 3 neural tissue predominates. In three of the remaining cases, the authors (Neuhäuser, 1906; Noguchi and $\frac{}{3}$ Lonser, 1961; Kourie and Roujeau, 1966) record 0 glial tissue in lymphatics or peripheral sinuses of nodes. This may indicate that the deposits are due $\frac{7}{0}$ to malignant change, probably low grade, occurring in the glial tissue spreading via the lymphatics to $N$ the peritoneum. Rupture of the teratoma with $N$ implantation of tissue in the peritoneum may explain the non-fatal cases of gliomatosis peritonei. $\frac{\omega}{\sigma}$ With known ruptured teratomas two types of symptom complexes are described. Acute rupture $\stackrel{\circ}{=}$ produces a chemical peritonitis, with great out- $\stackrel{D}{\perp}$ pouring of fluid, pyrexia, and shock, and was usually fatal until the advent of modern surgery 0 (Kirstner, 1952; Abitbol, Pomerance, and Mackles, 1959). A slower, smaller leakage, though it may $\frac{?}{\mathbb{D}}$ produce few or no symptoms, can lead to a peritoneal $\cong$ reaction mimicking tuberculosis or metastatic tumour, and showing microscopically a granuloma- $\delta$ 
tous lesion with foreign-body-type giant cells and lipid-laden macrophages (Quer, Dockerty, and Mayo, 1951; Stein and Kaye, 1954). These microscopic features have not been seen in most recorded cases of gliomatosis peritonei, but Kourie and Roujeau (1961) describe chronic inflammatory cells in the base of the peritoneal deposits, and both chronic inflammatory cells and a focus of foreign-body type giant cells were also present in our case. Also the cyst wall was breached at one point by glia and some mitotic activity seen at this point could well indicate an active penetration of the wall by tumour, albeit slow before its dissemination into the peritoneum. The case of Noguchi and Lonser, more than any other, suggests dissemination caused by surgical biopsy, and in Ackerman's case operation may also have played a part in the pathogenesis.

All three types of malignancy in teratoma may therefore be implicated in the pathogenesis of gliomatosis peritonei. The two fatal cases behaved as solid malignant teratomas and could be regarded as instances of the first type of malignancy. There does not appear to be any clear dividing line between the second and third types of malignancy in this group of patients. The third variety, illustrated by the present case report, is probably in most cases a variant of the second, in that there is malignant tumour of one element only, but of very low grade. The majority of cases are probably due to dissemination of low grade malignant or occasionally benign glial tissue following growth of glia through the cyst wall, traumatic (or other) rupture, or biopsy. In the last group the prognosis varies from fair to very good, depending probably on the precise mechanism causing dissemination.

We are grateful to Dr J. G. Azzopardi for his help and encouragement and to Professor C. V. Harrison for his valuable discussion. We also wish to thank Miss A. Tims for secretarial assistance and $\mathrm{Mr}$ W. Brackenbury for the photomicrographs.

\section{REFERENCES}

Abitbol, M. M., Pomerance, W., and Mackles, A. (1959). Obstet. and Gynec., 13, 198.

Ackerman, L. V. (1964). Surgical Pathology, 3rd ed., p. 754. Mosby, St. Louis.

Benirschke, K., Easterday, C., and Abramson, D. (1960). Obstet. and Gynec., 15, 512.

Blackwell, W. J., Dockerty, M. B., Masson, J. C., and Mussey, R. D. (1946). Amer. J. Obstet. Gynec., 51, 151.

Büttner, C. (1909). Mschr. Geburtsh. Gynäk., 30, 645.

Evans, R. W. (1966). Histological Appearances of Tumours, 2nd ed. p. 659. Livingstone, Edinburgh and London.

Fleischmann, C. (1905). Z. Geburtsh. Gynäk., 56, 396.

Helmke, K. (1938). Virchows Arch. path. Anat., 302, 509.

Hertig, A. T., and Gore, H. (1961). Tumours of the Female Sex Organs (Atlas of Tumor Pathology, Sect. IX, Fasc. 33), Pt. 3 p. 71. AFIP, Washington DC.

Kelley, R. B., and Scully, R. E. (1961). Cancer (Philad.), 14, 989.

Kistner, R. M. (1952). Obstet. gynec. Surv., 7, 603.

Kourie, M., and Roujeau, J. (1966). Arch. Anat. path., 14, 22.

Luse, S. A., and Vietti, T. (1968). Cancer (Philad.). 21, 8.

Marcial-Rojas, R. A., and Ramirez de Arellano, G. A. (1956). Ibid., 9, 523.

Neuhäuser, H. (1906). Arch. Gynak., 79, 696.

Noguchi, T. T., and Lonser, E. R. (1961). Amer. J. Obstet. Gynec., 82, 381 .

Nordmark, G. (1932). Acta obstet. gynec. scand., 12, 166.

Peterson, W. F. (1956). Amer. J. Obstet. Gynec., 72, 1094.

- (1957). Obstet. gynec. Surv., 12, 793.

Proskauer, G. G. (1946). Amer. J. Obstet. Gynec., 52, 845.

Quer, E. A., Dockerty, M. B., and Mayo, C. W. (1951). Proc. Mayo Clinic, 26, 489

Ruzicska, G. (excerpts) (1934). Orv. Hetil., 78, 654. (Abstr. in German), Ber. ges. Gynäck. Geburtsh., $28,44$.

Schairer, D. (1937). Z. Krebsforsch., 46, 254.

Stein, I. F. Sr, and Kaye, B. M. (1954). Amer. J. Obstet. Gynec., 67, 155

Stewart, M. J., Willis, R. A., and De Saram, G. S. W. (1939). J. Path. Bact., 49, 207.

Thurlbeck, W. M., and Scully, R. E. (1960). Cancer (Philad.), 13, 804. Willis, R. A. (1951). Teratomas. (Atlas of Tumor Pathology, Sect. III, Fasc. 9), p. 56. AFIP. Washington, DC. (1962). J. Path. Bact., 84, 237.

Woodruff, J. D., and Markley, R. L. (1957). Obstet. and Gynec., 9, 